This item was submitted to Loughborough's Research Repository by the author.

Items in Figshare are protected by copyright, with all rights reserved, unless otherwise indicated.

\title{
Digital health - a new medical cosmology? The case of 23andMe online genetic testing platform
}

\section{PLEASE CITE THE PUBLISHED VERSION}

https://doi.org/10.1111/1467-9566.12774

\section{PUBLISHER}

Wiley (@ Foundation for the Sociology of Health \& IIIness)

\section{VERSION}

AM (Accepted Manuscript)

\section{PUBLISHER STATEMENT}

This work is made available according to the conditions of the Creative Commons Attribution-NonCommercialNoDerivatives 4.0 International (CC BY-NC-ND 4.0) licence. Full details of this licence are available at: https://creativecommons.org/licenses/by-nc-nd/4.0/

\section{LICENCE}

CC BY-NC-ND 4.0

\section{REPOSITORY RECORD}

Saukko, Paula. 2019. "Digital Health - a New Medical Cosmology? the Case of 23andme Online Genetic Testing Platform". figshare. https://hdl.handle.net/2134/32616. 
Saukko, P. (accepted for publication). Digital health - a new medical cosmology? The case of 23andMe online genetic testing platform, Sociology of Health and Illness.

DIGITAL HEALTH - A NEW MEDICAL COSMOLOGY? THE CASE OF 23ANDME ONLINE GENETIC TESTING PLATFORM

This article argues that commercial digital health platforms and devices commodify participatory features of the digital creating a new medical cosmology. Drawing on sociology on medical cosmologies, research on digital media and marketing and an analysis of the 23andMe online genetic testing platform, I identify three features of this cosmology. First, digital health seeks to foment 'flow' or enjoyable, continuous immersion in health. Second, digital health configures its consumers as 'co-creators' of health data and knowledge together with companies and other consumers. Third, digital health frames medical knowledge as tentative, up for revision and scepticism by expert and lay science. The way in which digital health configures consumers as immersed, creative and sceptical gives it an open-ended and participatory air. However, the conceptual discussion and the analysis of the 23andMe platform highlight that these features represent commercial capture of the lifeworld, even if they appear radical against classical medical cosmologies. 


\section{Introduction}

Digital technologies are transforming consumption from a one-off purchase to a prolonged act of consuming taking place on elaborate online platforms and apps (Thrift, 2006). This strategy seeks to engage consumers in a more intense way and reflects a new business model, whereby companies extract value not only from selling products but also from selling their consumers' data, such as clicking and health data, to other companies. This business model underpins the burgeoning area of commercial digital health, which includes online platforms, apps and devices encouraging individuals to enhance their health and wellbeing, such as platforms that analyse and crowdsource, for example, DNA (23andMe), gut bacteria (Day Two, UBiome) or patient produced data on chronic diseases (PatientsLikeMe, CureTogether) and various self-tracking devices that track, for example, calories (MyFitnessPal, LoseIt), steps (FitBit, Jawbone) or sleep (FitBit, Beddit).

Digital health has been envisioned to usher a new era of crowdsourced preventive healthcare and research, whereby ‘always on' tracking devices enable people to collect data on their health, use it to change their behaviour and share and analyse it with peers and researchers (Swan, 2012). Critical social scientists have remarked that digital health intensifies selfsurveillance, individualisation of health and may be experienced as burdensome or depressing by users (Lupton, 2016). I am also critical of commercial digital health. However, I seek to conceptualise digital health in the context of sociological work on historical medical cosmologies (Jewson, 1976) in order to elucidate the novel ways it configures (Woolgar, 1990) (i) psychological states or affect (Gregg \& Seigworth, 2010) associated with health, (ii) patients or consumers and (iii) medical or health knowledge. 
I contend that, first, digital health seeks to foment 'flow,' a psychological state of enjoyable immersion (Csikszentmihalyi, 1991), which encourages consumers’ continuous engagement with digital products and services. Despite some overlap, this enjoyable immersion is different from what Armstrong (Armstrong, 1995) called ‘surveillance medicine,' which encourages individuals to change their behaviour to conform to 'normal' physical and mental states and is typically associated with anxiety. Surveillance medicine is, furthermore, different from classical 'hospital medicine,' which developed from late $18^{\text {th }}$ century onwards and suppressed emotions, reducing diseases into bodily lesions. Earlier still, in the $18^{\text {th }}$ century 'bedside medicine’ patron patients and family physicians located diseases in the broader psychosomatic context of the patient (Jewson, 1976).

Second, underpinned by a contradictory ethos of participatory commodification, digital health configures consumers as 'co-creators’ (Prahalad \& Ramaswamy, 2004), together with companies and other consumers, of health knowledge, data and products. This is different from surveillance medicine’s ‘expert patients’ (Department of Health, 2001), who would seek health information to conform to normalised notions of health (Armstrong, 1995; Nettleton, 2004). The expert patient is further different from hospital medicine’s patient, who was a passive object of medical knowledge and interventions. Bedside medicine’s affluent patron patient, on the contrary, was not passive but an active partner in producing diagnosis with her physician (Jewson, 1976).

Third, digital health configures health knowledge as data on what is normal or recommended, but this data is frequently configured as tentative and open for re-interpretation or criticism by consumers or 'citizen scientists,' (Prainsack, 2014) companies and science. This is 
different from the probabilistic evidence, based on scientific consensus, typical of surveillance medicine as well as the clinical, expert evidence on the body of hospital medicine. The tentative and co-created nature of digital health knowledge faintly resembles the knowledge created about symptoms between the patron patient and the physician in bedside medicine but the social, economic and technological ramifications of the two are very different.

Table 1 summarises the differences between digital health, surveillance medicine, hospital medicine and bedside medicine. It should be noted that the boundaries of the cosmologies are not clear-cut, and they do not necessarily supersede one another but are overlapping and contradictory. So, features of bedside medicine live on in primary care (May et al. 2006), and hospital medicine continues to reign in hospitals (Armstrong, 1995). The boundaries between surveillance medicine and digital health are blurry. My intention here is not to delineate an epochal shift in medicine. Rather, I seek to conceptualise the contradictory and beguiling ways in which commercial digital health is different from and similar to classical medical cosmologies. In what follows I will discuss digital health as a medical cosmology in more detail and then illustrate my points with analysing the case of the 23andMe online genetic testing platform. 


\begin{tabular}{|c|c|c|c|c|}
\hline & Bedside Medicine & $\begin{array}{l}\text { Hospital } \\
\text { Medicine }\end{array}$ & $\begin{array}{l}\text { Surveillance } \\
\text { Medicine }\end{array}$ & Digital Health \\
\hline $\begin{array}{l}\text { Psychological } \\
\text { state }\end{array}$ & $\begin{array}{l}\text { Psychosomatic } \\
\text { disturbance } \\
\text { underpins illness }\end{array}$ & $\begin{array}{l}\text { Suppression of } \\
\text { social/emotional } \\
\text { dimension of } \\
\text { health }\end{array}$ & $\begin{array}{l}\text { Anxiety, } \\
\text { behaviour change }\end{array}$ & $\begin{array}{l}\text { 'Flow,' enjoyable } \\
\text { immersion }\end{array}$ \\
\hline Patient/consumer & Patron patient & $\begin{array}{l}\text { Passive object of } \\
\text { clinical } \\
\text { knowledge, } \\
\text { intervention }\end{array}$ & $\begin{array}{l}\text { Expert patient, } \\
\text { seeking health } \\
\text { information }\end{array}$ & $\begin{array}{l}\text { Co-creator of } \\
\text { health data and } \\
\text { products with } \\
\text { companies }\end{array}$ \\
\hline $\begin{array}{l}\text { Medical/health } \\
\text { knowledge }\end{array}$ & $\begin{array}{l}\text { Conversation } \\
\text { between clinician } \\
\text { and patient about } \\
\text { illness }\end{array}$ & $\begin{array}{l}\text { Expert clinical } \\
\text { knowledge of the } \\
\text { body }\end{array}$ & $\begin{array}{l}\text { Consensus-based } \\
\text { probabilistic } \\
\text { evidence }\end{array}$ & $\begin{array}{l}\text { Tentative data, 'in } \\
\text { the making' }\end{array}$ \\
\hline
\end{tabular}

Table 1. Key characteristics of Bedside Medicine, Hospital Medicine, Surveillance Medicine and Digital Health.

\section{Digital Health -- a Medical Cosmology}

Jewson defines medical cosmologies as 'conceptual structures,' which make certain things ‘imaginable’ and others ‘inconceivable’ (Jewson, 1976), which is close to other notions, such as discursive formation, critical of power to naturalise certain ways of conceptualising the world (Nettleton, 2004). Jewson's work is useful as it examines shifts in medical imaginations also in relation to transformations in power and resources. He notes that the 
'patron,' who controlled the production of knowledge in bedside medicine was the affluent patient, whereas the patron of hospital medicine is the state and the hospital. Jewson further distinguishes 'laboratory medicine,' which locates diseases in biochemical processes; the patron of this medicine continued to be the state but hospital gave way to academy (Jewson, 1976). Armstrong does not explicitly discuss patronage, but state continues to control the production of knowledge in surveillance medicine, seeking to 'normalise' populations, although part of this control shifts to organisations in the community, such as primary care and child clinics (Armstrong, 1995). Nettleton (Nettleton, 2004) proposes that medicine has 'e-scaped’ from the clinic, with the increasing prominence of the Internet, and that the patron of medical knowledge is no longer solely the state and the academy but increasingly the consumer and the commercial enterprise.

I agree with Nettleton but suggest that the role of the commercial enterprise has become more prominent in digital health. Nettleton (Nettleton, 2004) observes that individuals are increasingly seeking biomedical and commercial health knowledge online and also producing such knowledge themselves, for example, in peer to peer online health support groups (Wright \& Bell, 2003). Diverse online health groups continue to exist. However, indicative of changes in peer to peer communication are platforms, such as PatientsLikeMe or CureTogether (currently owned by 23andMe), which bring together individuals with chronic diseases to crowdsource data on symptoms, side effects and treatments that have worked or not worked, to be sold on to commercial companies developing healthcare and wellness products (Van Dijck \& Poell, 2016). Large companies are also buying digital health devices to create integrated products and services. The free calorie and exercise tracking app, MyFitnessPal (with 80 million users) was recently purchased by Under Armour, a sports apparel company, developing a large connected fitness platform (Perez, 2015). The digital 
devices enable users to self-track and connect with others to support their fitness pursuits but they also enable companies to acquire data on individual behaviour to target ads and emails. Thus, in digital health the key commercial preoccupation is encouraging consumers not only to purchase products but also to keep producing data and be 'consistently engaged in an ongoing relationship’ (Dholakia, 2015).

The commercial preoccupation with engagement translates into a medical cosmology that underpins digital health. This cosmology shares features of surveillance medicine, but it is also different from it in three interconnected respects. First, the focus on engagement emphasises the affective dimension of medicine and health. Thrift observes that companies seek to create 'phenomenological encounters' with their consumers (Thrift, 2011), which in marketing is called a state of 'flow' or immersion that is experienced as intrinsically enjoyable, such as an athlete being 'in the zone’ (Csikszentmihalyi, 1991). Sociologists writing about medical cosmologies do not directly address the psychological or affective dimension of medicine. However, surveillance or preventive medicine encourages individuals to engage in self-surveillance to attain 'normal' health (Armstrong, 1995), which is associated with the psychology of anxiety and behaviour change. Digital health platforms and devices also frequently provide behavioural and risk data to encourage consumers to change their behaviour, and large studies and meta-analyses abound on whether this works (Michie et al. 2009). However, to keep consumers engaged digital health platforms and devices seek to achieve psychological and affective states associated with flow, such as a sense of control and presence of social interaction (Hoffman \& Novak, 2009; Pace, 2004). 
This leads to the second dimension in which digital health differs from surveillance medicine; it configures medical or health knowledge as co-created between companies and consumers. Surveillance medicine configured patients as more active than in hospital medicine, as they were encouraged to engage in self-surveillance and seek health and risk information (Armstrong, 1995). Nettleton observes that the development of e-scaped medicine further emphasised patient knowledges; the aim of consultations no longer being to achieve patient ‘compliance’ but 'concordance' between the views of clinicians and patients (Nettleton, 2004). However, expert clinical knowledge still features prominently in this configuration.

Drawing on various participatory paradigms in digital economy and culture, such as cocreation (Prahalad \& Ramaswamy, 2004), prosumption (Ritzer \& Jurgenson, 2010), big data (Kitchin, 2014) and citizen science (Prainsack, 2014) digital health gives a new twist to user knowledge. Clinicians do not necessarily feature in this equation (although they may), but consumers are configured as co-creating and analysing health data, such as symptom or behavioural data, through digital devices and platforms together with companies and other consumers. The extreme consumers in this respect would be members of the so called Quantified Self community, who use self-tracking devices in an innovative way to create alternative data, correlations and theories about health (Neff \& Nafus, 2016). However, the idea of consumer as co-creator of health knowledge and data has the usual problems associated with user-generated knowledge in digital environments; namely usually only a small minority of users engage in such creative activities, the digital platforms and devices constrain and guide creative possibilities (Van Dijck, 2009) and the data being generated by users is often harvested for corporate gain (Harris et al. 2016; Van Dijck \& Poell, 2016). 
Third, digital health configures medical or health knowledge differently from surveillance medicine. Armstrong notes that surveillance medicine changed the nature of medical knowledge from seeking to establish a binary division between health and disease to a statistical distribution of variables (BMI, cholesterol, blood pressure) throughout population (Armstrong, 1995). Digital health also relies on epidemiological risk factors, so digital devices and platforms frequently provide users data on epidemiological variables, such as BMI, steps per day, genes or levels of different microbes in stools, encouraging users to modulate their behaviour to achieve normal or recommended levels. However, digital health also encourages consumers to interrogate and generate their own data on, for example, symptoms, genes and quality of sleep, and to analyse this data alone, together or with companies in order to facilitate 'discoveries.' Thus, health knowledge or data becomes tentative, open for interpretation even critique by any user. This tentativeness seeks to keep users engaged, tinkering with their data. Furthermore, configuring knowledge and data as tentative also articulates the fact that they are not necessarily scientifically valid or accurate, belonging to the ambiguous regulatory and cultural terrain between medicine and consumer culture (Saukko et al. 2010).

On the whole, the way in which digital health configures consumers as immersed and health knowledges as co-created and tentative, makes it seem more open ended and participatory than traditional forms of clinician and science centred medicine. I grant that some forms of digital health can enhance participatory health knowledges and practices (Neff \& Nafus, 2016). However, I contend that the commercial realm that I explore here frequently commodifies and curtails the participatory potential of the digital, and my intention here is to make critical sense of this against the historical background. 
Methods

\section{3andMe}

To illustrate how digital health articulates a new medical cosmology, I will analyze the 23andMe direct-to-consumer genetic testing platform. 23andMe was established in 2006, and its co-founder Anne Wojcicki is the ex-wife of Sergey Brin, co-founder of Google. 23andMe offers a 'personal genome service,' which in its various incarnations has included genetic tests for risk factors for polygenic diseases (diseases, such as cardiovascular disease, which are not mainly caused by genes but complex interaction between genetic and environmental factors), being a carrier for genetic disorders, traits, drug response and ancestry. Consumers send saliva to the company, and the company makes the genetic test results available on an online platform. The interactive platform also gives access to a host of information and links, ability to connect with and compare genomes with 'relatives,' user forums and 'raw data' i.e. list of single nucleotide polymorphisms (SNPs or 'letter changes') decoded by the company's microarray, which can be further interpreted by consumers or a variety of software available online, such as Promethease. The company also invited consumers to consent to research and complete research surveys on the platform and sold the DNA and matching survey data to researchers and commercial companies (Harris et al. 2016; Tutton \& Prainsack, 2011). In 2013 the US Food and Drug Administration banned 23andMe from selling health-related tests for failing to provide evidence to back its marketing claims (Food and Drug Administration, 2013); the company launched revamped health tests in 2014 in the UK and Canada and in 2015 in the USA. In June 2015 the company announced it had sold a million tests (23andMe, 2015). 
23andMe offers a good case for examining features of digital health; its online platform is elaborate, has many interactive features, user forums, enables consumers to download and further examine their data and is underpinned by the dual business model of selling the service to consumers and consumers' data to other companies. Scholars have observed that the company frames its service using participatory rhetoric of 'open access,' 'community,' and 'reading' genomes whilst extracting 'unpaid labour' from its consumers by selling their data (Harris et al. 2016; O'Riordan, 2013; Van Dijck \& Poell, 2016). This article takes these conversations forward by conceptualising the alleged participatory nature of 23andMe in the broader context of medical cosmologies and digital health.

\section{Material and methods}

The material analysed for this article consists of 23andMe genetic testing platform. As part of a larger project we purchased the 23andMe test in 2008 and again in 2015, when the healthrelated tests were relaunched in the UK. The two tests gave access to different versions of the platform; the 2008 test gave access to genetic risk profiles, which synthesised information on genetic risk factors, estimating, if a consumer was at 'increased,' 'decreased' or 'average' risk of, for example, high blood pressure. These profiles were not available in the 2014 test, which interpreted less gene variants. Most other features, such as user forums, raw data and ability to connect with relatives were available on both versions of the platform. In 2017 the company launched a 'new 23andMe experience' and the two previous test results were made available as 'archives'. It should be noted that the UK 2014 and the US versions of the platform are different. The analysis is based on all three different versions of the platform (signposting which version is being discussed) as well as the Promethease report, which was obtained in 2016 by uploading 23andMe raw data onto the software. 
In consultation with our university's ethics committee, we were cleared from undergoing full ethical review to purchase the tests, as they were deemed publicly available. Similarly we were cleared from obtaining consent from participants in the company's discussion fora, as they were mainly information oriented and scarcely had a feel of an intimate, private conversation (like many support groups do) (Eysenbach \& Till, 2001). I also did not analyse the user conversations in terms of personal stories or use direct quotes but analysed how they configured consumers in more general terms.

To make sense of the 23andMe results and platform I took a lead from Woolgar's (Woolgar, 1990) classic notion of how designers of technology "configure” users or user experience. This means that designers imagine users to have certain qualities, or seek to engender certain qualities in them, which are then inscribed onto the technologies (Woolgar, 1990). Two things are of note here. First, configuring users is partly a semiotic activity, creating meanings, but it also has a material dimension, as it shapes the concrete design of the online platform, which facilitates certain actions but not others (Gillespie et al. 2014; Van Dijck, 2013). Second, whilst the way in which users are configured sets limits and expectations to actual users' activities, "real” users may employ technologies in unintended ways (Oudshoorn \& Pinch, 2003). In 23andMe's case the real and configured users sometimes blur, so that participants on user forums are real users but also become part of the product and its marketing. 
The results and web portal were analysed for themes, excluding information on ancestral genetics. Digital media requires a different type of analysis than media or interview texts, which can be simply coded. I analysed both the texts in the platform/report and their architecture and functions (Van Dijck, 2013). By architecture and functions I refer to the way in which the pages linked to information, enabled interaction between users and engaged the user (e.g. by sending emails). The analysis proceeded in the classic manner by identifying recurrent patterns in architecture, such as offering multiple links to incite users to further explore test results for specific diseases, which recurred in all results. Similarly, forum posts were examined for recurrent themes that occurred across the different sub-forums/texts. Material was not coded with software (not feasible for functions) but notes were taken of emergent themes and material was constantly compared to corroborate the findings (Glaser, 1965).

The web-material was mapped to broader policy and economic elements relevant to the “situation” (Clarke, 2005), such as the business model. I developed emergent themes by going back and forth between the material and relevant literature on medical cosmologies and digital media and marketing in an abductive (Timmermans \& Tavory, 2012) manner. So, I did not start by looking for aspects of medical cosmologies but related the material to this literature as it helped me to conceptualise features of the 23andMe platform that configured users and user experience in novel ways. In this process three broad themes were identified in terms of how the platform configured: (i) a psychological state of continuous immersion, (ii) consumers as co-creators of genetic knowledge and data, and (iii) scientific knowledge as tentative. In what follows these three themes will be explored in depth. 


\section{Fomenting Flow}

A characteristic feature of the 23andMe platform was that it encouraged consumers to spend time on and to return to it by offering links and interactive features for exploring and tinkering with one’s DNA. Thus, 23andMe encouraged “flow” or prolonged immersion, experienced as enjoyable (Csikszentmihalyi, 1991).

In all the different versions of the 23andMe platform consumers were informed that their 'genetic risk' for various conditions from celiac disease to Alzheimer's disease was 'elevated,' 'typical’ or 'decreased;' in the 2014 UK version consumers were informed they were 'likely to weigh more' or be of a 'similar weight' on a diet high in saturated fat based on genetic test results. In these instances the platform positioned consumers against a population norm, typical of surveillance medicine. Such risk information could, in principle, cause consumers to become anxious, and the platform also encouraged them to engage in selfsurveillance and behaviour change by offering healthy lifestyle advice, such as links to 'heart healthy diet', next to the test results.

However, adjacent to genetic risk profiles (2008) or risk factors (2014) the company linked to 'resources,' such as various disease organisations (Celiac.com, Alzheimer’s Association), Genetics Home Reference, scientific articles, tools for recording and assessing family history of disease, laboratories offering further testing and relevant threads on user forums. By following the links consumers could learn about symptoms, prevention, new research, other genes associated with the conditions (not in the 23andMe results), US restaurants offering 
gluten-free menus and discussions on lay theories and experiences of family history. Thus, 23andMe platform did not only offer its consumers a description of risk and preventive advice, but it also enabled consumers to follow different paths and explore the results in terms of science, genetic data, prevention, restaurants, conversations and getting in touch with others. The structure enabled consumers to forge different paths within and beyond the company's platform and enhanced consumers' sense of control -- a key feature of flow (Hoffman \& Novak, 2009) -- and encouraged spending more time exploring.

It has been observed that, somewhat counter-intuitively, goal-oriented information seeking scores higher in terms of flow, such as losing track of time in following interesting leads, than non-goal oriented behaviour or play (Novak et al. 2003). 23andMe platform clearly capitalised on this aspect of flow, facilitating, for example, seeking information about a specific gene variant or health condition of interest. However, the links on the platform opened up many different paths, also fostering non-directional or experiential searching i.e. surfing, following new leads out of curiosity rather than driven by a specific goal (Pace, 2004). So, the digital platform blurred goal-oriented information seeking and more idle play, so that seeking a piece of health or scientific information could expand into a longer, flowdriven immersion in a network of links leading to different parts of the platform and to the web beyond, including scientific and lay debates and speculations about the association between specific genes and conditions or triggers or treatments for conditions, such as gluten sensitivity.

The 23andMe platform also cultivated another key element of flow, telepresence i.e. the extent to which one feels 'present' in the mediated environment (Hoffman \& Novak, 2009). 
Telepresence often refers to vividness of images but also includes social presence, feeling part of social interaction, which in gaming studies has been associated with a sense of fellowship, competition, acquiring status and helping others (Korhonen et al. 2009; Yee, 2006). 23andMe fostered social presence through multiple user fora, where consumers asked and answered questions about their results, helped each other to find information on, for example, associations between genes and conditions from the 'raw data' and shared their genetic results and experiences of disease and created speculative theories about genes and health. These fora fostered a sense of fellowship and enabled some users to acquire status as lay experts, answering questions, coming up with explanations and directing others to further resources. When browsing the fora, the number of experts, who usually answered the questions for newcomers and others, was small. Most likely the rule of thumb in digital marketing that $1 \%$ of users create most of the content on forums, corroborated by research on health fora (van Mierlo, 2014), holds true on 23andMe platform. The “superusers,” nevertheless, create value and fresh content for everyone, also drawing some of the lurking majority to browse and get immersed in the conversations, even if they do not post themselves.

Overall, the psychological state 23andMe platform sought to configure was tinged with anxiety about genetic health risks and motivation to take preventive action, fitting with surveillance medicine. However, the features on the platform also configured a flow-inducing experience of wandering along and getting lost in exploring different paths, companionship and conversations. This user experience appears more open ended, sociable and enjoyment driven than the anxiety tinged drive to make people conform to specific bodily or behavioural norms, characteristic of surveillance medicine. However, I contend that the flow enhancing features represent commodification of the playful and pluralistic potential of the digital. 
Whilst the links and conversations were many, they did not direct consumers down any path but to mainly seek associations between health and DNA and information on preventing or further analysing the risk and keep engaging with the platform.

\section{Consumers as co-creators}

23andMe also configured consumers similar to surveillance medicine’s 'expert patients' (Department of Health, 2001), who actively seek expert information on health risks and prevention. The multiple links, interactive features and data on the 23andMe’s platform, however, afforded consumers to move from consuming information to producing or creating genetic knowledge. Consumers could, for example, follow the links on both 2008 and 2014 platforms to further genetic and non-genetic tests and risk calculators—which, for example, estimate the risk of heart disease based on cholesterol and blood pressure levels, self-reported exercise and diet and family history_and personalise or co-create (Prahalad \& Ramaswamy, 2004) the service or risk of a specific disease using both 23andMe results and other results or data.

Consumers could further explore links to scientific literature, user discussions on specific genes and disease, and analyse their genetic 'raw data.' Nettleton has noted that in e-scaped medicine patients also produce medical knowledge; concepts such as concordance and online peer-to-peer support are predicated on the idea that lay knowledge, such as embodied knowledge of side effects, should be taken seriously (Nettleton, 2004). This type of lay medical knowledge was frequently produced on 23andMe user forums, and consumers 
related their genetic test results to their personal or family history of a specific disease, which has been observed to be a common way for people to assess the salience of genetic information (Scott et al. 2005). They also rebuffed genetic information, when their genetic risk was assessed as high but no one in their family had developed the disease, configuring consumers who tempe0red genetics with personal assessment of diseases running in the family. The forums also encouraged consumers to create their own explanations about associations between genes as well as other factors and disease. For example, in the celiac disease forum consumers could ask fairly mundane questions about, whether specific symptoms, such as being underweight, could be associated with the condition. Others made suggestions as to what could cause sensitivity to wheat, such as the use of antibiotics destroying gut flora or norovirus resistance (asking if there was a SNP associated with the latter) or noted that they had different markers for the condition in 23andMe and Promethease.

However, digital health also gives a different twist to lay knowledge, turning it into data, so that lay users may, for example, crowdsource data on embodied experiences of side effects to drugs in order to make discoveries together. Users are configured as co-creators of data in several respects on the 23andMe platform. First, consumers are invited to take part in research or 'crowdsource' data in various ways. In 2017 the platform invited consumers to answer half a dozen survey questions, such as 'When living in a climate that does not get much sunlight in the winter, do you tend to become depressed during the winter months?', which then earned one access to an 'insight.' These insights were 'findings' based on responses from 23andMe consumers, such as an association between a gene variant and being 'filled with rage' by the sound of others eating (misophonia) or characteristics typical of 'first born’ and 'second born’ siblings, such as altruism. In this instance 23andMe configured 
consumers as creating data, which translated directly into discoveries of correlations between answers to survey questions (being raged by eating noises) and DNA and between phenotypic data (birth order and character traits). At the same time, consumers had to 'earn’ these insights by answering questions, configuring research participation not as an altruistic but 'entrepreneurial' activity, whereby individuals take part to gain knowledge about themselves (Tutton \& Prainsack, 2011).

Second, the practice of contributing data to find correlations continued on the user forums, as a form of citizen science (Prainsack, 2014). For example, an unusually popular thread on a user forum, focused on the MTHFR gene spanned years and a few thousands of posts. The original contributor had conducted a lay study on Facebook with people with MTHFR, polling how many had experienced miscarriages and the polling continued on 23andMe. In the responses individuals volunteered their miscarriage experiences and genetic markers. They also shared experiences of many other health problems from bipolar disorder to irritable bowel disease, experiences with non-understanding doctors and links to scientific articles and to practitioners of alternative medicine. Some posts questioned or repudiated the suggestions about a genetic link or remedies. The original MTHFR lay study mimicked the research 23andMe invited its consumers to participate in by answering questions and matching it with DNA. However, the thread ended up a rather unwieldy conglomeration of different knowledges and opinions, creating theories, practices and doubts about a specific gene.

Configuring consumers as co-creators of health knowledge and data created a sense of users not being passive recipients of information. Rather, consumers were configured as active producers of knowledge to suit their needs or data to create new discoveries, and sometimes 
far-fetched theories, about themselves. This notion of consumers resonates with the marketing paradigm of companies and consumers creating personalised products and value together (Prahalad \& Ramaswamy, 2004), the discourses on digital big data that can be analysed by everyone (Kitchin, 2014) and on citizen science that could democratise science (Prainsack, 2014). However, the process of co-creation on the platform and associated Facebook groups was restricted to mainly exploring correlations between DNA and/or individualistic parameters of disease and behaviour. Furthermore, the co-creation between consumers and the company in terms of research also commodified DNA and experiences into goods to be shared and traded between 23andMe and third parties, such as pharma.

\section{Tentative knowledges}

In 2013 the US FDA banned 23andMe from selling its health-related genetic tests, as the company failed to provide evidence to support its marketing claims (Food and Drug Administration, 2013). The decision referred to, for example, the genetic risk profiles, which estimated whether consumers' genetic risk for diverse diseases and conditions was 'increased’ or 'decreased.' The profiles were accompanied with bar charts and numerical estimates of individual consumer’s risk vis a vis population risk, similar to surveillance medicine’s probabilities (Armstrong, 1995). However, contrary to surveillance medicine, these risk estimates were not agreed upon by the scientific consensus, and this is why FDA banned them.

Thus, throughout its history 23andMe has shifted between framing the information on genetic associations it sells as factual or deterministic health information and as tentative, knowledge 
in the making. Consequently, 23andMe’s platform has been replete with disclaimers about the nature of the knowledge, noting that the results are for 'informational' purposes and not to ‘diagnose' illness or disease. Further, the risk profiles, included in the test prior to 2013, were accompanied by a star-rating (from 1 to 5 ) indicating the 'confidence' of the scientific evidence backing each estimate. On one hand this presentation enhanced trust in the scientific nature of the estimates (referring to 'confidence'), on the other hand it fostered a sense of doubt about their meaning. However, perhaps the most concrete way in which 23andMe configured the knowledge contained in the risk profiles as tentative was the fact that the company kept changing the estimates. 23andMe sent its consumers emails, alerting them to 'new results' when new associations between gene variants and health conditions were added to the profiles. This aimed, obviously, to encourage consumers to return to the platform, but as the new associations were added to the profiles the risk estimates of individual consumers changed. Thus, one could start off with being at 'increased' genetic risk for obesity and end up at 'typical' risk. The shifting risk estimates illustrate the contradictions embedded in configuring medical knowledge as consisting of constantly created data. On one hand it configured data as abreast with latest scientific or lay scientific discoveries but, on the other hand, it configured it as tentative and fluid, even speculative.

The Promethease reports included associations between disease risk and particular gene variants, and, similar to 23andMe risk profiles, the software grouped gene variants or SNPs into "good” and "bad” news about health. However, generally Promethease configured genetic knowledge more as fragmentary snippets of scientific data relevant for exploring rather than medical information on how to take care of health. The report contained gene variants in the hundreds, associated with diseases and conditions (from bipolar disorder to low density lipoprotein (“bad”) cholesterol). Further, the report incorporated tens of gene 
variants associated with the same or similar condition (cholesterol, heart disease, cardiovascular disease etc,) or a single gene could be associated with many conditions (bipolar disorder and anorexia) in different parts of the report i.e. not grouped together. This way of presenting the gene variants configured genetic knowledge not as unified but as fragmentary pieces of a puzzle, which consumers had to put together themselves.

The Promethease report was visually crude, conveying, in specialist vocabulary, the research behind the SNPs and a link to SNPedia (open access database on SNPs), which included further links to scientific articles and mathematical estimates of associations. The language used on the service was often informal, referring to specific gene variants as "boring," "dubious” or “deep magic.” Thus, Promethease configured knowledge and data as unfinished, difficult or impressive and informal and to be reinterpreted by interested lay consumers.

23andMe also configured knowledge as multiple; both 23andMe and Promethease presented their consumers different genes, which could decrease or increase the risk of a specific disease. Even if 23andMe original risk profiles added these risks together (but Promethease did not), it configured genetic knowledge as consisting of multiple, contradictory and tentative pieces or perspectives. As discussed in the previous section, the user forums configured knowledge as multiple by fuelling contradictory and diverse lay theories and practices about genes and disease.

Overall, 23andMe configured genetic knowledge similar to surveillance medicine as abstract probabilities or risks (Armstrong, 1995). However, 23andMe and Promethease also 
configured genetic knowledge as tentative, fluid, fragmentary, informal and multiple. These ways of configuring knowledge are similar to postmodern conceptions, which reflect the erosion of the authority of traditional modern institutions, such as science (Nowotny et al. 2001). The erosion of "grand narratives," such as scientific progress, was celebrated to cultivate a generally ironic stance toward all knowledge (Baudrillard, 1977) or to lead to the proliferation of multiple "micro" narratives or knowledges, which could challenge the established truths of the powerful (Lyotard, 1984).

However, theories of postmodernity were developed in the context of "old" media, where many knowledges or irony were seen as potential means of resisting the onslaught of dominant information. Literature on postmodernity about scepticism and multiple knowledges helps to make sense of 23andMe. However, digital marketing has turned some of the tenets of postmodernity on their heads, as encouraging individuals to doubt and produce data and knowledge has become a way for companies to seduce consumers to immerse themselves in and propagate their products.

Discussion

It can be asked whether, or to what extent, 23andMe platform is indicative of features of commercial digital health more generally. Self-tracking devices, such as MyFitnessPal, frequently incorporate advanced features -- such as ability to track historical trends in data, multiple types of data and their relationships and ability to connect with others for support and analysis on user forums - to foster engagement. Self-tracking devices and crowdsourcing 
platforms, such as PatientsLikeMe, also encourage consumers to co-create the data together with companies; the Quantified Self movement being an intense case of members using selftracking devices to create their own data and alternative analyses and understandings of health (Neff \& Nafus, 2016). Digital health platforms and devices also oscillate between framing health knowledge on, for example, stress levels or gut bacteria, as scientific and framing it as tentative, knowledge in the making. Thus, whilst different digital health applications have their specificities, the themes recurring on 23andMe platform resonate in the field.

Locating digital health in the context of medical cosmologies brings its historicity and specificity into clearer light. Jewson (Jewson, 1976) chronicled how the modernist rise of hospital and laboratory medicine abstracted medical knowledge away from the sick man of bedside medicine and into the institutional spaces of the hospital and the laboratory. Armstrong contends that surveillance medicine continued this abstraction, rendering medical knowledge abstract probabilities on what is normal and expanding the jurisdiction of medicine or medicalisation into everyday life (Armstrong, 1995). Nettleton argues that as of late medicine has ‘e-scaped’ further from the clinic into the virtual reality, where medical knowledge becomes more heterogeneous, produced by experts, lay people, organisations and enterprises (Nettleton, 2004).

I contend that digital health is the next stage in medicine e-scaping the clinic, further blurring the boundaries of medicine and consumer and digital culture (Saukko et al. 2010). Digital health platforms and self-tracking devices are mostly available direct-to-consumers online or through retail, such as department stores. This broader availability represents medicalization 
of further areas of everyday life. However, I have here argued that this new form of medicine and medicalization operates differently from previous cosmologies, as it increasingly borrows from digital culture and marketing. Digital health has characteristics typical of surveillance medicine, offering consumers knowledge on what is 'normal' (steps per day, genetic risk) and encouraging them to change their behaviour. Yet, the ways in which commercial digital health configures an enjoyable user experience of co-creating tentative knowledges makes it seem less paternalistic and more open ended than the prescriptive health advice propagated by expert organisations, typical of surveillance medicine, or the strict hierarchy typical of hospital medicine.

However, I argue that digital health represents a commercial capture of the pluralistic and participatory promises of online health. The potential of the digital is to open up a network of connections to different health knowledges, bringing users together to create new and alternative knowledges and be able to take a critical stance towards knowledge claims. Digital health has commodified these participatory promises, so that once largely peer-led peer-to-peer health support groups have become a stable of commercial digital health gadgets and platforms or captured by companies, as in the case of PatientsLikeMe. In this situation commercial digital health applications structure spaces of conversations and practices that best serve the companies and typically repeat worn-out ideas of individual responsibility for health and genetic determinism. The goal of encouraging consumers to explore and create knowledge is not to create new ideas but to engage with the product or service and to produce data to be sold on for other companies. 
The way in which commercial digital health has commodified participatory features of the digital is part of a general trend in digital media. As noted by commentators, such as Burgess (2015), the early diffuse, author-centred practices on platforms, such as YouTube and Flickr, have given way to garnering large audiences and selling data from activities to market research and advertising. This is an instance of what Thrift calls 'Lifeworld Inc,' which uses new technologies to produce an improvised experience, seeming to belong to the 'lifeworld' rather than the 'system' but represents corporate capture of the everyday (Thrift, 2011). As Manowich (Manovich, 2009, pp. 323-24), drawing on Lefebvre (Lefebvre, 1991), argues “companies have developed strategies that mimic people’s tactics of bricolage, reassembly, and remix' making the 'logic of everyday tactics' become the 'logic of corporate strategies' and eventually selling people's tactics back to them.”

Much research on digital health has addressed it as surveillance or preventive medicine, exploring or speculating, whether it improves health or whether it burdens its users with managing their health as individuals and foments anxiety (Swan, 2012, Lupton, 2016). Addressing digital health in terms of the participatory promise of the digital raises different questions: Does digital health enhance its consumers' agency to come up with new personal and social understandings and practices of health? Or does it simply configure a sense of creative agency whilst encouraging tinkering with normative healthy lifestyle? How are the knowledges produced by consumers’ creative agency used and by whom?

As a final note it should be remembered that the way in which digital health configures its consumers does not necessarily determine the way in which real users (particularly the majority not hanging out in the fora) use the platforms and devices. Research on 23andMe 
consumers has observed that they were 'savvy' about the limitations of the tests (McGowan et al. 2010) or sceptical of the results (Ruckenstein, 2017), although these studies did not explore how users engaged with the platform. We recently observed that ordinary or casual users of MyFitnessPal calorie counting app did not use its advanced features (retrospective data, forums) and used it temporarily to lose weight (Didžiokaitè et al. 2017). Whilst our participants complied with the premise of the technology and counted calories to lose weight, they did not engage with it intensely, reminiscent of earlier studies on reluctant users of the Internet for health information (Henwood et al. 2003). More research is clearly needed on both commercial digital health and casual users, rather than extreme or fringe cases, such as the Quantified Self community. 


\section{References}

23andMe. (2015, June 18). The power of one million. Retrieved from https://blog.23andme.com/news/one-in-a-million/

Armstrong, D. (1995) The rise of surveillance medicine. Sociology of Health \& Illness, 17(3), 393-404.

Baudrillard, J. (1977) The implosion of meaning in the media and the implosion of the social in the masses. In K. Woodward (Ed.), The myth of information (137-48). Madison: Coda Press.

Burgess, J. (2015) From 'broadcast yourself' to ‘follow your interests': making over social media, International Journal of Cultural Studies, 18(3), 281-285

Clarke, A. (2005) Situational analysis: Grounded theory after the postmodern turn. Thousand Oaks: Sage.

Csikszentmihalyi, M. (1991). Flow: The psychology of optimal experience. New York: Harper.

Department of Health. (2001). The expert patient: A new approach to chronic disease management for the 21st century. London.

Dholakia, S. (2015, September 8). A new definition of marketing: Lessons from MyFitnessPal. Marketing Land.

Didžiokaitè, G. Saukko, P. Greiffenhagen, C. (2017) The mundane experience of everyday calorie trackers: Beyond the metaphor of Quantified Self, New Media and Society, DOI:10.1177/1461444817698478. 
Eysenbach, G., \& Till, J. E. (2001). Ethical issues in qualitative research on internet communities. BMJ (Clinical Research Ed.), 323(7321), 1103-1105.

Food and Drug Administration. (2013). Warning letter to 23andMe inc. Retrieved from http://www.fda.gov/iceci/enforcementactions/warningletters/2013/ucm376296.htm

Gillespie, T., Boczkowski, P., \& Foot, K. (Eds.). (2014). Media technologies: Essays on communication, materiality, and society. Cambridge: MIT Press.

Glaser, B. (1965). The constant comparative method of qualitative analysis. Social Problems, 12(4), 436-445.

Gregg, M., \& Seigworth, G. (Eds.) (2010) The affect theory reader. Durham: Duke University Press.

Harris, A., Kelly, S., \& Wyatt, S. (2016) CyberGenetics: Health genetics and new media London: Routledge.

Henwood, F., Wyatt, S., Hart, A., \& Smith, J. (2003) 'Ignorance is bliss sometimes’: Constraints on the emergence of the 'informed patient'in the changing landscapes of health information. Sociology of Health \& Illness, 25(6), 589-607.

Hoffman, D. L., \& Novak, T. P. (2009) Flow online: Lessons learned and future prospects. Journal of Interactive Marketing, 23(1), 23-34.

Jewson, N. D. (1976) The disappearance of the sick-man from medical cosmology, 17701870. Sociology, 10(2), 225-244.

Kitchin, R. (2014) Big data, new epistemologies and paradigm shifts. Big Data \& Society, 1(1), 1-12. 
Korhonen, H., Montola, M., \& Arrasvuori, J. (2009) Understanding playful user experience through digital games. International Conference on Designing Pleasurable Products and Interfaces, 274-285.

Lefebvre, H. (1991). Critique of everyday life. London: Verso.

Lupton, D. (2016). The quantified self. Cambridge: Polity.

Lyotard, J. F. (1984). The postmodern condition. Minneapolis: University of Minnesota Press.

Manovich, L. (2009) The practice of everyday (media) life: From mass consumption to mass cultural production? Critical Inquiry, 35(2), 319-331.

May, C., Rapley, T., Moreira, T., Finch, T., \& Heaven, B. (2006) Technogovernance: Evidence, subjectivity, and the clinical encounter in primary care medicine. Social Science \& Medicine, 62(4), 1022-1030.

McGowan, M. Fishman, J. \& Lambrix, M. (2010) Personal genomics and individual identities: Motivations and moral imperatives of early users. New Genetics and Society, 29(3), 261-290.

Michie, S., Abraham, C., Whittington, C., McAteer, J., \& Gupta, S. (2009). Effective techniques in healthy eating and physical activity interventions: A meta-regression. Health Psychology, 28(6), 690.

Neff, G., \& Nafus, D. (2016). Self-tracking. Cambridge: MIT Press.

Nettleton, S. (2004) The emergence of e-scaped medicine. Sociology, 38(4), 661-79. 
Novak, T. Hoffman, D. \& Duhachek, A. (2003) The influence of goal-directed and experiential activities on online flow experiences. Journal of Consumer Psychology, 13(1), 3-16.

Nowotny, H., Scott, P., \& Gibbons, M. (2001) Re-thinking science: Knowledge and the public in an age of uncertainty. London: Polity.

O'Riordan, K. (2013) Biodigital publics: Personal genomes as digital media artefacts. Science as Culture, 22(4), 516-539.

Oudshoorn, N., \& Pinch, T. (2003). How users matter: The co-construction of users and technology. Cambridge: MIT Press.

Pace, S. (2004). A grounded theory of the flow experiences of web users, International Journal of Human-Computer Studies, 60(3), 327-363.

Perez, S. (2015, February 5). Under armour snatches up health and fitness trackers endomondo and MyFitnessPal. TechCrunch.

Prahalad, C. K., \& Ramaswamy, V. (2004). Co-creation experiences: The next practice in value creation. Journal of Interactive Marketing, 18(3), 5-14.

Prainsack, B. (2014) The powers of participatory medicine. PLoS Biology, 12(4), e1001837.

Ritzer, G., \& Jurgenson, N. (2010). Production, consumption, prosumption the nature of capitalism in the age of the digital 'prosumer'. Journal of Consumer Culture, 10(1), 1336.

Ruckenstein, M. (2017). Keeping data alive: Talking DTC genetic testing. Information, Communication \& Society, 20, 7, 1024-39. 
Saukko, P. Reed, M., Britten, N., \& Hogarth, S. (2010). Negotiating the boundary between medicine and consumer culture: Online marketing of nutrigenetic tests. Social Science \& Medicine (1982), 70(5), 744-753.

Scott, S. Prior, L. Wood, F. \& Gray, J. (2005). Repositioning the patient: The implications of being 'at risk’. Social Science \& Medicine, 60(8), 1869-1879.

Swan, M. (2012). Health 2050: The realization of personalized medicine through crowdsourcing, the quantified self, and the participatory biocitizen. Journal of Personalized Medicine, 2(3), 93-118.

Thrift, N. (2006). Re-inventing invention: New tendencies in capitalist commodification. Economy and Society, 35(02), 279-306.

Thrift, N. (2011) Lifeworld inc.: And what to do about it. Environment and Planning D: Society and Space, 29(1), 5-26.

Timmermans, S. \& Tavory, I. (2012) Theory construction in qualitative research: From grounded theory to abductive analysis, Social Theory, 30, 3, 167-186.

Tutton, R., \& Prainsack, B. (2011) Enterprising or altruistic selves? making up research subjects in genetics research. Sociology of Health \& Illness, 33(7), 1081-1095.

Van Dijck, J. (2009). Users like you? theorizing agency in user-generated content. Media, Culture \& Society, 31(1), 41-58.

Van Dijck, J. (2013). The culture of connectivity. Oxford: Oxford University Press.

Van Dijck, J., \& Poell, T. (2016). Understanding the promises and premises of online health platforms. Big Data \& Society, 3(1), 2053951716654173. 
van Mierlo, T. (2014). The $1 \%$ rule in four digital health social networks: An observational study. Journal of Medical Internet Research, 16(2), e33.

Woolgar, S. (1990). Configuring the user: The case of usability trials. The Sociological Review, 38(S1), 58-99.

Wright, K. B., \& Bell, S. B. (2003). Health-related support groups on the internet: Linking empirical findings to social support and computer-mediated communication theory. Journal of Health Psychology, 8(1), 39-54.

Yee, N. (2006). Motivations for play in online games. CyberPsychology \& Behavior, 9(6), 772-775. 